\title{
Evaluate the effects of metabolic syndrome in adolescents and children
}

Discussion

Rui-Min Jia ${ }^{a, *}$, Xiao-Ning Yan ${ }^{b}$ Jing Sun ${ }^{a}$

aNursing College, Shanxi University of Chinese Medicine, Jinzhong, Shanxi 030619, China

${ }^{b}$ Clinical Practice of the Fourth College, Shanxi University of Chinese Medicine, Jinzhong, Shanxi 030619, China

Received: 1 February 2020; Accepted: 26 February 2019; Published: 20 September 2020

\begin{abstract}
The metabolic syndrome (MS) in adolescents and children can cause serious consequences that lead researchers to pay efforts to study in such area. Presently, MS definition is still not standardized. Different versions of MS definition have been used by numerous studies, which may be a problem to identify MS and then to predict and prevent clinical diseases. The pediatric literature shows that insulin resistance and obesity might be the key underlying pathophysiology of MS to cause many related diseases. High prevalence of MS is in overweight and obese children and adolescents. This article focuses on such above issues and also effects of MS on two main disease outcomes: cardiovascular disease and type 2 diabetes.
\end{abstract}

Keywords: metabolic syndrome $\bullet$ children/adolescents • type 2 diabetes $\bullet$ cardiovascular disease $\bullet$ metabolic syndrome definition • insulin resistance $\bullet$ obesity

(c) Shanxi Medical Periodical Press.

\section{Introduction}

The interest of metabolic syndrome (MS) has been increased since the last century. This concept was first exposed in the 1920s and the publication indicated that MS was associated with hypertension, gout, and diabetes. Following, in the 1940s, some ground-breaking research by Vague were conducted on the correlation between central body fat distribution and several risk factors of cardiovascular disease (CVD). Later, in the 1990s, the lecture of Reaven's Banting started the modern era of MS. He drew new attention to the correlation between insulin resistance and many metabolic abnormalities linked to MS also named as "syndrome X."
Recently, the definition of MS is a cluster of risk factors for atherosclerotic CVD and type 2 diabetes mellitus (T2DM) which consist of obesity, glucose intolerance, abnormal lipid profile, and hypertension. ${ }^{2}$ In the Ozanne and Hales' study, the possible mechanisms of developing T2DM and MS in regard to fetal development were reviewed. ${ }^{3}$ It indicated that MS development may be associated with early growth restriction in utero which might lead to onset of the pathological processes of T2DM in early childhood. Childhood MS might raise the risk of T2DM, CVD, and other related diseases, for instance, nonalcoholic fatty liver disease and polycystic ovary syndrome in life. ${ }^{4}$ Additionally, MS in childhood may likely track into adulthood, but the evidence

How to cite this article: Jia RM, Yan XN, Sun J. Evaluate the effects of metabolic syndrome in adolescents and children. Front Nurs. 2020;3:287-292. 
is limited, owing to limited studies that track participants during childhood to adulthood period and always use secondary data that may not be strong enough to reveal such tracking. Until at present, little has been known how well MS in children can predict adult disease. ${ }^{5}$

Recently, the common recognitions about the components of pediatric MS and its important predictability in the risk of T2DM and CVD development have been made during the accumulation of research evidence. This article aims to discuss those two diseases as the consequence of MS through MS definition and the major underlying pathophysiology.

\section{MS definitions in adolescents and children}

The definition of MS in children and adolescents has not been unified, and it is usually based on the adult standards (such as the International Diabetes Federation (IDF) guidelines) and varies with different ethnic populations by different criteria and cutoff points. ${ }^{6}$ Five similar studies were chosen and examined their MS definition, among which some criteria for defining MS were used in later studies. Those studies were conducted among the American adolescents to predict the prevalence of MS. Four of them used the modified adults version to define MS (the National Cholesterol Education ProgrammeAdult Treatment Panel III) (NCEP-ATP III) (see Table 1 for specific criteria of NCEP-ATP III). ${ }^{7-11}$ Another study used MS definition derived from the 2007 child IDF.11,12 Findings showed that several cutoff points of variables are different and ambiguous, even using the same resource to classify MS.

Specifically, for defining variables with varied levels, fasting triglyceride (TG) was defined as $\geq 150 \mathrm{mg} / \mathrm{dL}$ by Park et al. ${ }^{8}$; however, defined as $\geq 100 \mathrm{mg} / \mathrm{dL}$ by de Ferranti et al. ${ }^{7}$ and Cook et al. ${ }^{9}$; and defined as $\geq 110 \mathrm{mg} / \mathrm{dL}$ by Duncan et al. ${ }^{10}$ For defining variables whether considering gender's difference, waist circumference (WC) was defined as $>75$ th percentile by de Ferranti et al. ${ }^{7}$ and defined as $\geq 90$ th percentile by Cook et al., ${ }^{9}$ Duncan et al., ${ }^{10}$ and Ford et al., ${ }^{11}$ but defined separately in genders: $>102 \mathrm{~cm}$ for male and $>88 \mathrm{~cm}$ for female in Park et al. ${ }^{8}$

Furthermore, some studies defined MS by using specific ethnic or race criteria. However, which level should be selected as criteria for MS in children does not have a universal agreement. ${ }^{5}$ Different thresholds for some of the essential variables are used by studies, which may lead to the difficulty of diagnosing MS, estimating MS prevalence and the clinical consequences. According to those studies, a standardized definition of children may be needed even though they had a common disadvantage that was measured body mass index (BMI) instead of WC. Tables 2 and 3 show the specific range of characteristics and measures used commonly for diagnosing MS in children.

\begin{tabular}{llll}
\hline Items & All & Female & Male \\
\hline \hline Central obesity & & Waist $\geq 102 \mathrm{~cm}$ & Waist $\geq 88 \mathrm{~cm}$ \\
Blood pressure & Systolic $\geq 130 \mathrm{mmHg} ;$ & & \\
& Diastolic $\geq 85 \mathrm{mmHg}$ & & \\
Triglycerides & & $\geq 1.7 \mathrm{mmol} / \mathrm{L}$ & $<1.0 \mathrm{mmol} / \mathrm{Lmol} / \mathrm{L}$ \\
HDL-C & & $<1.3 \mathrm{mmol} / \mathrm{L}$ & $\geq 6.1 \mathrm{mmol} / \mathrm{L}$ \\
\hline
\end{tabular}

NCEP-ATP III, National Cholesterol Education Programme-Adult Treatment Panel III; MS, metabolic syndrome; HDL-C, high-density lipoprotein cholesterol.

Table 1. NCEP-ATP III definition of MS in adults.

\begin{tabular}{lll}
\hline Risk factors & de Ferranti et al. ${ }^{7}$ & Cook et al. $^{9}$ \\
\hline \hline Abdominal obesity & $>75$ percentile & $\geq 90$ percentile \\
HDL-C & Female $<50 \mathrm{mg} / \mathrm{dL} ;$ male $<45 \mathrm{mg} / \mathrm{dL}$ & $\leq 40 \mathrm{mg} / \mathrm{dL} \quad \geq 90$ percentile \\
Triglycerides & $\geq 100 \mathrm{mg} / \mathrm{dL}$ & $\geq 110 \mathrm{mg} / \mathrm{dL} \quad \geq 10$ percentile \\
Fasting glucose & $\geq 110 \mathrm{mg} / \mathrm{dL}$ & $\geq 110 \mathrm{mg} / \mathrm{dL} \quad>90$ percentile $\quad>90$ percentile \\
Blood pressure & $>90$ percentile & IGT:ADA criterion \\
\hline
\end{tabular}

MS, metabolic syndrome; HDL-C, high-density lipoprotein cholesterol; ADA, American Diabetes Association; IGT, impaired glucose tolerance.

Table 2. Published definitions of MS in pediatrics. 


\begin{tabular}{|c|c|c|c|}
\hline \multirow[t]{2}{*}{ Items } & \multicolumn{3}{|c|}{ Age group } \\
\hline & $6-10$ years & $10-16$ years & $>16$ years \\
\hline Obesity (WC) & $\geq 90$ percentile & $\geq 90$ percentile (or adult cutoff) & Using adult criteria \\
\hline Triglycerides & MS cannot be diagnosed & $\geq 150 \mathrm{mg} / \mathrm{dL}$ & Using adult criteria \\
\hline HDL-C & MS cannot be diagnosed & $<40 \mathrm{mg} / \mathrm{dL}$ & Using adult criteria \\
\hline Blood pressure & MS cannot be diagnosed & Systolic: $\geq 130 \mathrm{mmHg}$; diastolic: $\geq 85 \mathrm{mmHg}$ & Using adult criteria \\
\hline Glucose & MS cannot be diagnosed & OGTE: $\geq 5.6 \mathrm{mmol} / \mathrm{L} ;$ or known type 2 diabetes & Using adult criteria \\
\hline
\end{tabular}

IDF, International Diabetes Federation; MS, metabolic syndrome; WC, waist circumference; HDL-C, high-density lipoprotein cholesterol; OGTE, oral glucose tolerance test.

Table 3. IDF definition of MS in adolescents and children

However, a single MS definition to adolescents and children might not be proper to show problems in this age, owing to the unique physical development during childhood. ${ }^{10}$ Endocrine levels may be influenced by pubertal development and genders. A typical previous study indicated that the adverse association existed among puberty, body fat, age, insulin resistance, and adiponectin. Compared with prepubertal children, pubertal children had apparently lower adiponectin level $(P<0.001)$. Especially, adiponectin was shown to be at lower level in pubertal girls, and no difference of adiponectin had been found between prepubertal girls and boys. The negative association had been observed among body fat $(r=0.44 ; P=0.002)$, age $(r=0.41 ; P=0.003)$, insulin resistance $(r=0.33$; $P=0.016)$, and adiponectin. ${ }^{13}$ Hence, for adolescents and children, to define abnormalities by using single cutoff point might not be suitable. A recent study combined clinical indicators and diseases as criteria. Specifically, five criteria were: TG serum concentration $\geq 150 \mathrm{mg} / \mathrm{dL} /$ treating TG; in male high-density lipoprotein cholesterol (HDL-C) $<40 \mathrm{mg} / \mathrm{dL} / \mathrm{in}$ female $<50 \mathrm{mg} /$ $\mathrm{dL} /$ treating HDL-C; $\mathrm{BMI}>$ age and 95th percentile; glucose concentration $\geq 100 \mathrm{mg} / \mathrm{dL} /$ treating hyperglycemia; systolic blood pressure (SBP) $\geq 130 \mathrm{mmHg}$ or/ and diastolic blood pressure (DBP) $\geq 85 \mathrm{mmHg} /$ treating hypertension. ${ }^{12}$

Additionally, there are also some other difficulties in determining a standardized definition of MS in children. For example, ethnic differences exist in developing MS. ${ }^{14}$ MS criteria may need consider ethnic variations and immigrant population.

\section{Impact of MS on CVD and T2DM}

MS is defined as a cluster of high TGs, obesity, low HDL cholesterol, high blood pressure, and insulin resistance which associate with the early progress of coronary atherosclerosis and T2DM. ${ }^{2,3}$ In the pediatric literature, lot of effort has been made to explore the relationship among CVD, T2DM, and MS. MS in children may be an indicator of CVD and T2DM in their adult period, but limited data directly explore the impact of MS on disease outcomes in adolescents and children. The consistent finding was that there is a strong positive relationship between children with MS and the development of CVD in their later life. Youth with MS were at two- to threefold risk of having subclinical atherosclerosis (carotid intima-media thickness) and T2DM compared with healthy youth. ${ }^{15}$

However, the correlation between the severity of MS and the level of adiponectin and fasting insulin has been not clear enough. One recent study pointed that childhood MS Z-scores had a positive association with insulin levels in adult $(P<0.001)$ and a negative association with levels of adiponectin $(P=0.01)$. For individual analyses, greater levels of insulin and MS Z-score during adulthood were significantly related to greater odds of occurrence CVD and diabetes over the following 11.2 years $(P<0.001)$.

Therefore, MS severity had a long-term link to the level of adiponectin and insulin, and it independently and consistently correlated with T2DM and CVD, which may be owing to the potential, environmental, and genetic influence over time. So, in the future, MS severity may be used as a risk predictor of these diseases. ${ }^{16}$

The correlation among MS, T2DM, and CVD varied with ethnicity and race. The black population with MS has a greater risk of CVD than the white population with MS. The reason may be that MS induces some nontraditional risk factors of CVD including C-reactive protein, high level of low-density homocysteine, lipoprotein oxidation, adiponectin, lipoprotein a, and plasminogen activator inhibitor-1, and so on. Therefore, to predict and examine CVD and T2DM caused by MS should consider ethnicity/race and also nontraditional and traditional risk factors. Researchers suggested that nontraditional risk factors need to be added in the definition of MS. ${ }^{17}$ 


\section{Major pathophysiology of MS contributing to consequences of CVD and T2DM}

\subsection{Insulin resistance}

Insulin resistance may be a core abnormality of a clustering of CVD and T2DM risk factors. ${ }^{15}$ Higher baseline insulin concentration in youth gradually develops MS, which provides the evidence that insulin resistance might precede and enhance the development of MS in childhood. Increased insulin levels had greatly adverse levels of other risk factors that subsequently led to MS, regardless of race, age, and sex. According to the report of $\mathrm{WHO}$, in 2017 about 425 million people had diabetes worldwide, and by 2040 the number will increase to 642 million. Among diabetes, there will be about $70 \%$ people with MS, mainly at puberty age. ${ }^{18}$

Normally people with higher insulin concentration had lower level of HDL-C and higher level of DBP and $\mathrm{SBP}$, very low-density lipoprotein (VLDL) cholesterol, low-density lipoprotein (LDL) cholesterol, total cholesterol, TGs, and glucose, compared with people with lower insulin level. ${ }^{19}$ Obesity $(\mathrm{WC}>90 \mathrm{~cm})$, triacylglycerol level $>150 \mathrm{mg} / \mathrm{dL}$, blood glucose $>100 \mathrm{mg} / \mathrm{dL}$, $\mathrm{HDL}-\mathrm{C}<40 \mathrm{mg} / \mathrm{dL}$, and blood pressure $>130 / 85 \mathrm{mg} / \mathrm{dL}$ had a strong association with insulin resistance. ${ }^{20}$

\subsection{Obesity}

According to a recent report study, approximately $44.3 \%$ of obese children have characteristics of MS, and lower percentage of normal weight children have only one risk factor of MS. ${ }^{21}$ Another study even showed a higher prevalence $(70 \%$ obesity with $\mathrm{SM})$ through modified guidelines of $\mathrm{WHO} .^{22}$

Obesity, particularly, abdominal obesity may directly contribute to the progress of MS and cardiovascular risk. It has been known that childhood obesity is related to increased blood pressure, low HDL-C, increased TGs, abnormal glucose levels, reduced vascular function, and insulin resistance. ${ }^{17}$ Central obesity $(\mathrm{WC}>90 \mathrm{~cm})$ is strongly associated with MS, on which genetic variants may have an effect. Obese genes and lipid metabolism can drive genetic predisposition to MS. Examining genetic variants in MS polygenic scores may be a way to identify the child and subsequently the adult belonging to a high-risk group to early targeting interventions. ${ }^{20}$

Central obesity induces MS that may also be due to modulating particular signaling pathways, the growth hormone/insulin-like growth factor-1 and ghrelin signaling axis, through which it regulates metabolic homeostasis and energy balance. ${ }^{23}$

\subsection{Both insulin resistance and obesity}

Either in the adult or pediatric literature, insulin resistance and obesity are pointed to be always tightly connected with each other and to be as underlying etiological factors to develop MS that may then give rise to CVD and T2DM. The degree of body fat was significantly related to reverting impaired glucose tolerance to normal glucose tolerance and T2DM development. Change in body weight was negatively associated with changes in glucose level and insulin sensitivity. Further reduction of insulin sensitivity exists in youth with a developed T2DM, which was related to a continued weight gain and abnormal body composition profiles such as truncal subcutaneous fat, excess body fat, and abdominal adiposity. ${ }^{24}$ According to a recent study, $53 \%$ obese children and adolescents have insulin resistance. ${ }^{22}$ Another study showed that MS with high triacylglycerol and central obesity were correlated with high risk of insulin resistance (OR: 24.4; 95\% Cl: 5.19e114.42) and (OR: 9.4; $95 \% \mathrm{Cl}: 3.09 \mathrm{e} 28.68)$, respectively. ${ }^{25}$

However, not all obese children or adolescents with impaired metabolism of carbohydrate develop MS and even CVD or T2DM. Probably, other elements such as pathological and metabolic factors and lifestyle factors are involved. Currently, it has been reported that the lead of urinary level was positively correlated to $M S .{ }^{26}$ Unhealthy lifestyle (including smoking, low income, low physical activity, and alcohol intake) has a negative effect on diseases development. ${ }^{27}$ Overall, the interaction between the elements of MS and between other metabolic factors may ultimately lead to disease.

\section{Conclusions}

There are several points that may need to be emphasized for the future study. First, the definition of MS may need to be standardized. Number of studies have been attempted to characterize MS in children. However, to date, there has been no universally accepted MS definition in children, which may lead to the situation where it is hard to diagnose MS and to estimate its clinical consequences, and subsequently hard to take early treatment. To define the standardized concept of MS may need complete understanding of the underlying pathophysiology and consideration of variations concerning related factors including age, ethnicity, sex, family history, and lifestyle behaviors. Second, the true picture of diabetic and cardiometabolic risk may be due to overweight/obesity and insulin resistance, but that may not mean that other traditional components of MS, pathological and metabolic factors, and genetic factors can be ignored to predict CVD and T2DM. 


\section{Ethical approval}

Ethical issues are not involved in this paper.

\section{References}

1. Weiss R, Dziura J, Burgert TS, et al. Obesity and the metabolic syndrome in children and adolescents. N Engl J Med. 2004;350:2362-2374.

2. Namayandeh SM, Karimi $A$, Fallahzadeh $H$, et al. The incidence rate of diabetes mellitus (type II) and its related risk factors: a 10-year longitudinal study of Yazd Healthy Heart Cohort (YHHC). Iran Diabetes Metab Syndr Clin Res Rev. 2019;13:1437-1441.

3. Ozanne SE, Hales CN. Early programming of glucose-insulin metabolism. Trends Endocrinol Metab. 2002;13:368-373.

4. MacPherson M, de Groh M, Loukine L, Prud'homme D, Dubois L. Prevalence of metabolic syndrome and its risk factors in Canadian children and adolescents: Canadian health measures survey cycle 1 (2007-2009) and cycle 2 (2009-2011). Chronic Dis Inj Can. 2016;36:32-40.

5. Faienza MF, Wang DQ H, Frühbeck $\mathrm{G}$, et al. The dangerous link between childhood and adulthood predictors of obesity and metabolic syndrome. Intern Emerg Med. 2016;11:175-182.

6. Nambiar S, Truby H, Davies PS, Baxter K. Use of the waist-height ratio to predict metabolic syndrome in obese children and adolescents. J Paediatr Child Health. 2013;49:E281-E287.

7. de Ferranti SD, Gauvreau K, Ludwig DS, Neufeld EJ, Newburger JW, Rifai N. Prevalence of the metabolic syndrome in American adolescents. Circulation. 2004;110:2494-2497.

8. Park YW, Zhu S, Palaniappan L, Heshka S, Carnethon MR, Heymsfield SB. The metabolic syndrome: prevalence and associated risk factor findings in the US population from the third national health and nutrition examination survey, 1988-1994. Arch Intern Med. 2003;163:427-436.

9. Cook S, Weitzman M, Auinger $P$, Nguyen $M$, Dietz WH. Prevalence of a metabolic syndrome phenotype in adolescents: findings from the third national health and nutrition examination survey, 1988-1994. Arch Pediatr Adolesc Med. 2003;157:821-827.

10. Duncan GE, Li SM, Zhou XH. Prevalence and trends of a metabolic syndrome phenotype among U.S. adolescents, 1999-2000. Diabetes Care. 2004;27:2438-2443.

\section{Conflicts of interest}

All contributing authors declare no conflicts of interest.
11. Ford ES, Li C, Zhao G, Pearson WS, Mokdad AH. Prevalence of the metabolic syndrome among U.S. adolescents using the definition from the international diabetes federation. Diabetes Care. 2008;31:587-589.

12. Cruz ML, Weigensberg MJ, Huang TT-K, Ball G, Shaibi GQ, Goran MI. The metabolic syndrome in overweight Hispanic youth and the role of insulin sensitivity. J Clin Endocrinol Metab. 2004;89:108-113.

13. Benmohammed K. Metabolic syndrome in adolescents: definition based on regression of IDF adult cut-off point. Public Health. 2016;141:88-94.

14. Cook WK, Tseng W, Tam C, et al. Ethnic-group socioeconomic status as an indicator of community-level disadvantage: a study of overweight/obesity in Asian American adolescents. Soc Sci Med. 2017;184:15-22

15. Francisco V, Ruiz-Fernández C, Pino J, et al. Adipokines: linking metabolic syndrome, the immune system, and arthritic diseases. Biochem Pharmacol. 2019;165:196-206.

16. DeBoer MD, Gurka MJ, Morrison JA, et al. Interrelationships between the severity of metabolic syndrome, insulin and adiponectin and their relationship to future type 2 diabetes and cardiovascular disease. Int J Obes. 2016;40:1353-1359.

17. Osei K, Gaillard T._Disparities in cardiovascular disease and type 2 diabetes risk factors in Blacks and Whites: dissecting racial paradox of metabolic syndrome. Front Endocrinol. 2017;8:1-10.

18. Soliman HM, Mosaad YO, Ibrahim A. The prevalence and the clinical profile of metabolic syndrome in children and adolescents with Type 1 diabetes. Diabetes Metab Syndr Clin Res Rev. 2019;13:1723-1732.

19. Belhayara MI, Mellouk Z, Hamdaoui MS, et al. Relationship between the insulin resistance and circulating predictive biochemical markers in metabolic syndrome among young adults in western Algeria. Clin Res Rev. 2019;13:504-509.

20. Nagrani R, Foraita R, Gianfagna F, et al. Common genetic variation in obesity, lipid transfer genes and risk of metabolic syndrome: results from IDEFICS/I. Family study and meta-analysis. Sci Rep. 2020;10:7189-7202. 
21. Radetti G, Fanolla A, Grugni G, et al. Indexes of adiposity and body composition in the prediction of metabolic syndrome in obese children and adolescents: which is the best? Nutr Metab Cardiovasc Dis. 2019;29:1189-1196.

22. Barseem NF, Helwa MA. Homeostatic model assessment of insulin resistance as a predictor of metabolic syndrome: consequences of obesity in children and adolescents. Egyptian Pediatric Association Gazette. 2015;63:19-23.

23. Yu AP, Ugwu FN, Tam BT, et al. Obestatin and growth hormone reveal the interaction of central obesity and other cardio metabolic risk factors of metabolic syndrome. Sci Rep, 2020;10:5495-5505.

24. Gaston SA, Tulve NS, Ferguson TF. Abdominal obesity, metabolic dysfunction, and metabolic syndrome in U.S. adolescents: National Health and Nutrition Examination Survey 2011-2016. Ann Epidemiol. 2019;30:30-36.

25. Mansyur MA, Bakri S, Patellongi IJ, et al. The association betweenlmetabolic syndrome components, low-grade systemic inflammation and insulin resistance in non-diabetic Indonesian adolescent male. Clin Nutr ESPEN. 2019;001:1-6.

26. Lin CY, Huang PC, Wu C, et al. Association between urine lead levels and cardiovascular disease risk factors, carotid intima-media thickness and metabolic syndrome in adolescents and young adults. Int J Hyg Environ Health. 2020;223:248-255.

27. Aguirre PF, Coca A, Aguirre MF, et al. Waist-toheight ratio and sedentary lifestyle as predictors of metabolic syndrome in children in Ecuador. Hipertensión riesgo vascular, 2018;35:101-109. 